The aim of the physician should be to reëstablish these functions, and thus increase the oxidation of the peptones, and relieve the renal congestion.

Among the means best suited to this purpose are the ordinary swcatings, or, in obstinate cases, hot air baths always followed by cool or cold shower baths ; preparations of arsenic, and inhalations of oxygen. The dict should bo vegetable or starchy, with but very little meat.

W. F. M.

\title{
CAUSE OF CONSUMPTION.
}

To the Editors of the Boston Medical and Surgical Journal.

AT the request of the author, I send you a synopsis of a new theory of the cause of consumption,* by Henry MacCormac, M.D., of Belfast, Ireland. This theory is set forth in a series of papers, read before various foreign Medical Socicties, at different times since 1855, and accompanied by a long and eloquent introduction. The following formula, in small capitals, contains his idea.

"Wherever the air habitually respircd, has been respired in whole, or in part, before, there tubercular deposits are found; and wherever the air habitually respired, has not been respired, in whole or in part, before, there tubercular deposits are impossible, and consumption and scrofula are unknown."

He further claims that, "for the first tine in the history of disease, the proximate source of tubercle is capable of exact demonstration. Tuberculous and scrofulous deposits, whether in the offspring of scrofulous and consumptive parents, or others, are the invariable results of insufficient, imperfect respiratory function and re-breathed air. Hence the carbon is retained unoxidized; in other words, is not discharged from the blood, and is deposited, mainly as a hydro-carbon, in the lungs or other organs, as tubercle."

This theory he supports by an analysis of the composition of tubercle, showing a large percentage of carbon; by the prevalence of consumption and scrofula in connection with bad ventilation of slecping apartments; by their special prevalence, in classes whose occupations subject them to the influence of re-breathed air, by day as well as by night; and by the cures he has seen effected solely by the constant supply of unbreathed air.

He also refers to the production of tubercle in the animals in menageries, and in rabbits confined in boxes for the purposes of experiment.

Whether his theory is fully demonstrated by the facts he presents, must be left to those more competent to analyze them. The

* Cunsumption, as engendored by Re-breathed Air, \&c. Its Prevention and Possible Cure. By Henry MacCormac, M.D. London: Longman, Green, Longman, Roberts \& Greon. 2u Edition. 
author's position, as well as the importance of the subject, command attention to his views, and it is his wish to subject them to the criticism of the profession in Boston. If his theory is sound, consumption may always be prevented, often cured. The victim of an inherited tubercular diathesis need no longer sit, with folded hands, awaiting his doom. The annual decimation of infants may be reduced onehalf, and the general mortality one-fourth, by the annihilation of this great scourge of the human race!

Opposed to his theory, is the non-coexistence of consumption with certain cases of imperfect oxygenation of the blood; as in malformations and obstructive discases of the heart, pressure of abdominal tumors, and of the gravid uterus, \&c.

The extensive researches of $\mathrm{Dr}$. Bowditch in the same field, show an important connection between consumption and the cold and dampness of certain localities. It is hard, also, to disconnect from this question those other great causes of perverted nutrition, insufficient food and want of exercise. Bad hygienic conditions are sure to be associated, and sanitary reforms being directed against them all, it is hard to estimate the cxact influence of each, or to determine the specific influence of either of them. The mortality in English prisons has indeed been greatly reduced, but not wholly by improved ventilation, as improvements in diet, clothing, heating, bathing and exercise have generally accompanied it.

The ventilation of hospitals and public buildings reccives due attention with us, but in the work-shops and dwellings of the peoplo it is neglected. The majority do not enjoy morc than half a minimum allowance of fresh air in their slecping rooms, and this small cube is often unchanged till morning. The aim in our climate is, to keep out the cold, by stoves, double windows, listing and weather strips, which effectually prevent all, save accidental ventilation. Many work-shops, factories, and most day-rooms are no better. What specific effects this state of things will in the long run producc, is a question worth considering.

T. W. Fisher.

\section{ZBbliograpbital Notices.}

Forty-third Annual Report of the Officers of the Retreat for the Insane, at Hartford, Conn., April, 1867.

Tne Retreat is not a joint stock institution, but a charity. It is controlled by an association of gentlemen, without distinction of party or sect, called the "Society for the Relief of the Insane," and these gentlemen derive no pecuniary benefit from it in any way. The Society meets annually and appoints a Treasurer, a Board of Directors and the executive officers. To this Board the general management of the Institution is confided. The Directors appoint a committee of Managers, a committec of Medical Visitors, and a visiting committee 